\title{
Agricultural drought monitoring: Progress, challenges, and prospects
}

\author{
LIU Xianfeng ${ }^{1,2}$, ZHU Xiufang ${ }^{1,2}$, 'PAN Yaozhong ${ }^{1,2}$, LI Shuangshuang ${ }^{1,3}$, \\ LIU Yanxu ${ }^{4}$, MA Yuqi ${ }^{2}$
}

1. State Key Laboratory of Earth Surface Processes and Resource Ecology, Beijing Normal University, Beijing 100875, China;

2. College of Resources Science \& Technology, Beijing Normal University, Beijing 100875, China;

3. Academy of Disaster Reduction and Emergency Management, Beijing Normal University, Beijing 100875, China;

4. College of Urban and Environmental Sciences, Peking University, Beijing 100871, China

\begin{abstract}
In this paper, we compared the concept of agricultural drought and its relationship with other types of droughts and reviewed the progress of research on agricultural drought monitoring indices on the basis of station data and remote sensing. Applicability and limitations of different drought monitoring indices were also compared. Meanwhile, development history and the latest progress in agricultural drought monitoring were evaluated through statistics and document comparison, suggesting a transformation in agricultural drought monitoring from traditional single meteorological monitoring indices to meteorology and remote sensing-integrated monitoring indices. Finally, an analysis of current challenges in agricultural drought monitoring revealed future research prospects for agricultural drought monitoring, such as investigating the mechanism underlying agricultural drought, identifying factors that influence agricultural drought, developing multi-spatiotemporal scales models for agricultural drought monitoring, coupling qualitative and quantitative agricultural drought evaluation models, and improving the application levels of remote sensing data in agricultural drought monitoring.
\end{abstract}

Keywords: agricultural drought; drought monitoring; research progress; research prospect

\section{Introduction}

Global climate change, which is both the biggest problem and the most complicated challenge faced by human beings, has attracted the attention of the public and governments worldwide (Ye, 1992). The frequency and intensity of extreme climate events like drought have increased significantly since the 1970s. Since extreme climate events tend to be more

Received: 2015-11-10 Accepted: 2015-12-15

Foundation: Major Project of High-resolution Earth Observation System

Author: Liu Xianfeng (1986-), PhD Candidate, specialized in resource and environmental remote sensing and disaster remote sensing. E-mail: liuxianfeng7987@163.com

"Corresponding author: Pan Yaozhong (1965-), PhD and Professor, specialized in statistics and disaster remote sensing research. E-mail: pyz@bnu.edu.cn 
abnormal, unexpected, unpredictable, and sensitive to climate change, they are considered the main source of terrestrial ecosystem instability and have a substantial impact on sustainable development of both ecosystems and human economy (Liu et al., 2015; Stocker et al., 2013). Moreover, according to the earth system model, the risk of global drought will further increase in the 21st century (Dai, 2011). Therefore, how to react to and reduce drought and its impact has become an urgent scientific issue. Among the various adverse effects of drought, its influence on agriculture is most significant and direct. According to statistics, economic loss due to global meteorological disasters accounts for $85 \%$ of that due to all natural disasters, and economic loss due to drought accounts for more than $50 \%$ of that due to all meteorological disasters. Agriculture, which is related to national food security and social stability, is severely constrained by the climate and weather (Dai, 2012). Therefore, research on agricultural drought has become the focus of governments and scholars worldwide.

Past experiences in dealing with major natural disasters have shown that risk aversion is more rewarding than disaster relief with respect to reducing hazard risks (Wu et al., 2015), and the 3rd UN World Conference on Disaster Reduction also emphasized the importance and urgency of disaster monitoring and loss preventing when establishing the goals and priorities of disaster reduction. Although agricultural drought monitoring is important for reducing disaster loss and impact, it is still poorly understood. Organizations and scholars worldwide have performed a series of fruitful research projects on the cause of drought and monitoring methods and influence of agricultural drought. For example, the Group on Earth Observations (GEO) has developed the Global Agricultural Monitoring (GLAM) initiative to evaluate agricultural drought monitoring (Fan et al., 2014). Some scholars have also summarized the concept of drought and its monitoring methods and developing trends systematically and comprehensively (AghaKouchak et al., 2015; Chen et al., 2009; Heim, 2002; Mishra et al., 2010; Wang et al., 2005; Zhang et al., 2011; Zhang et al., 2014). Since agricultural drought is associated with various subjects like agriculture, meteorology, hydrology, and plant physiology and it is an interaction field for natural systems and artificial systems, research on agricultural drought monitoring is faced with many difficulties both theoretically and technically (Li et al., 2012). Previous reports have mostly summarized agricultural drought studies with respect to drought indices, but a comprehensive understanding of agricultural drought monitoring field remained unclear. Therefore, it is necessary to sort out the monitoring methods and development history of agricultural drought.

Since agriculture provides the foundation of China's economy and climate change will directly influence our food security and sustainable development (Zhao et al., 2010), breakthroughs are needed in the study of agricultural drought, both theoretically and technically, to help us deal with the negative influence of complicated climate change on agricultural production. In particular, summarizing the current status of agricultural drought monitoring is an important step for further theoretical studies and evaluation of novel methods. Therefore, the aim of this study was to summarize the concept, monitoring indices for agricultural drought, and review the development history and recent progress of agricultural drought monitoring through document statistical analysis and citation of important papers. Furthermore, challenges and weaknesses of previous studies and the future prospects have both been discussed to meet the practical need of the government to monitor agricultural drought. 


\section{Agricultural drought and monitoring methods}

\subsection{Concept of agricultural drought}

Generally, drought is classified into meteorological drought, agricultural drought, hydrological drought, and socio-economic drought. Meteorological drought refers to the water deficit caused by an imbalance between precipitation and evaporation. Agricultural drought reflects the extent to which soil moisture is lower than the least requirement of plants by analyzing the characteristics of soil moisture and morphology of plants during growth. Hydrological drought occurs when river flow is lower than the normal value or when the water level of an aquifer decreases; and socio-economic drought is the phenomenon in which production and consumption are affected by the lack of water in both the natural system and human socio-economic system (Chen et al., 2009). Although the definitions of the four types of droughts are different, they are all water-deficit phenomena caused by the lack of precipitation, and they are all connected (Figure 1). When precipitation decreases, meteorological drought occurs first, followed by agricultural drought and hydrological drought, which gradually occur because of continuous water evaporation. Since agricultural drought is mainly concerned with water deficit in crops because of a reduction in water supply in the soil, loss of soil moisture caused by the decreases in precipitation is the earliest phenomenon. Because of transpiration, water in crops cannot meet the basic needs for physiological activities, and crop growth is suppressed, resulting in a reduction in crop yield or even failure. The influence of drought on different stages of plant growth is significantly different. Hydrological drought mainly causes a reduction in water resources in rivers and reservoirs and a decline in groundwater levels. Socio-economic drought is triggered when agricultural and hydrological droughts develop to a certain degree. Therefore, here is a simple understanding of the connection between all types of droughts: agricultural drought and hydrological drought refer to the influence of meteorological drought on agriculture and the hydrological system separately, and socio-economic drought refers to the influence of meteorological

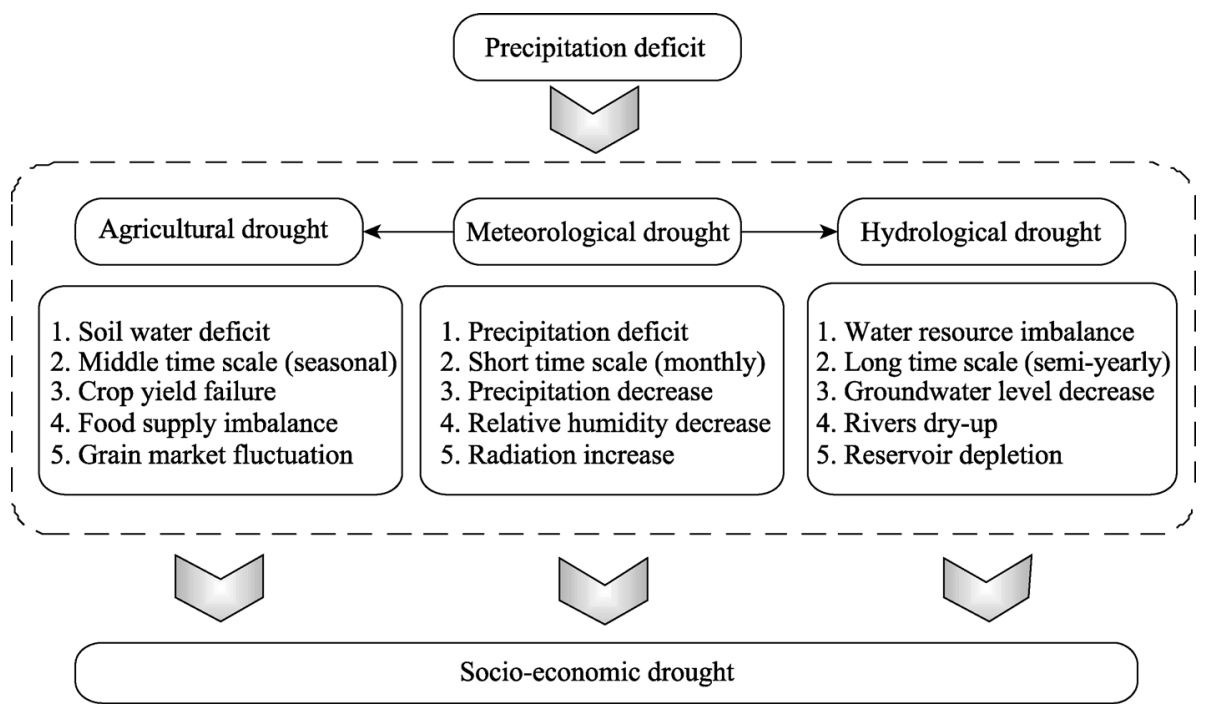

Figure 1 Drought transfer processes and interactions 
drought on the socio-economic system (Christopher et al., 2012; Zhang et al., 2014).

\subsection{Assessment methods for agricultural drought monitoring}

Drought events are normally characterized by drought indices because the phenomenon is very complicated and the time, development process, and scope of influence are difficult to observe directly (Dai, 2011; Heim et al., 2002; Solomon et al., 2007). Currently, there are hundreds of indices to characterize drought, and they can be divided into site-based and remote sensing-based indices (Heim et al., 2002). Site-based indices include the standardized precipitation index (SPI), Palmer drought severity index (PDSI), and crop moisture index (CMI). Remote sensing-based indices are divided into indices based on bare surface (including thermal inertia and microwave moisture inversion) and indices based on vegetation cover. Vegetation-based drought monitoring indices can be further classified into crop morphological indices (like condition vegetation index and normalized vegetation index), crop physiological indices (like canopy temperature and canopy moisture content), and crop comprehensive indices (like vegetation supply water index and temperature-vegetationdrought index) (Figure 2 and Table 1).

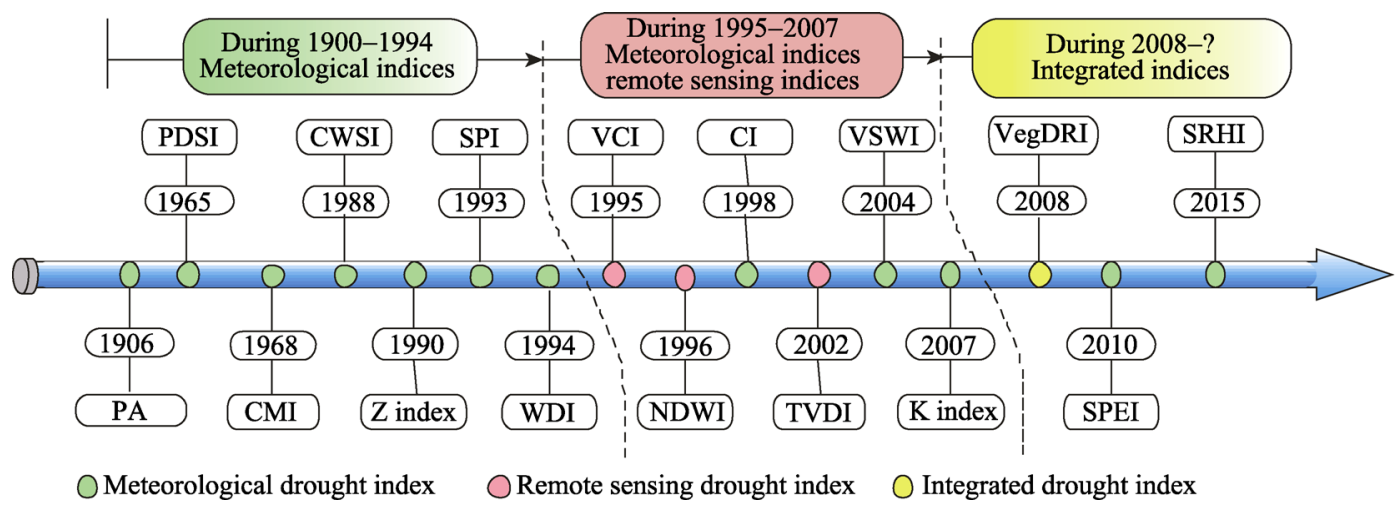

Figure 2 Development process of drought monitoring indices

\subsubsection{Site-based drought monitoring}

Research on drought monitoring initiated in the US in the early 20th century, and most early indices only took precipitation into consideration (Gibbs, 1967; Henry, 1906; Kincer, 1919; Marcovitch, 1930; McGuire et al., 1957; McQuigg, 1954; Munger, 1916; Van Rooy, 1965) until Palmer raised the concept of the current climate suitable precipitation (Palmer, 1965) and proposed PDSI in 1965. This index became a milestone for drought monitoring and was used both in America and other parts of the world and by governments and scholars as a drought monitoring tool. Palmer took the water demand of crops into consideration and developed CMI, which was broadly applied for agricultural drought monitoring (Palmer, 1968). Scholars gradually understood the limitations of PDSI (Alley, 1984; Heddinghaus et al., 1991), and Wells (2004) reported self-calibrated PDSI to overcome the limitations. The biggest advantage of this improved index is that it decides different calibration parameters according to the local climate characteristics and therefore improves the ability of PDSI to 
Table 1 Main meteorological and agricultural drought monitoring indices

\begin{tabular}{|c|c|c|c|}
\hline Indices & $\begin{array}{l}\text { Proposed } \\
\text { time }\end{array}$ & Main author & Indices description \\
\hline PA & 1906 & Henry (1906) & $\begin{array}{l}\text { Drought occurs when precipitation during } 21 \text { days or a longer } \\
\text { period is equal to or less than } 30 \% \text { of the normal precipitation. }\end{array}$ \\
\hline PDSI & 1965 & Palmer (1965) & $\begin{array}{l}\text { Water deficit of actual water supply continues to be less than the } \\
\text { local climate water supply in a period. }\end{array}$ \\
\hline CMI & 1968 & Palmer (1968) & $\begin{array}{l}\text { Mainly used for agricultural drought monitoring and analyzing } \\
\text { conditions of crop drought on the basis of a water balance model. }\end{array}$ \\
\hline CWSI & 1988 & Jackson (1988) & $\begin{array}{l}\text { Determines crop water deficit by considering the relationship } \\
\text { between soil moisture and farmland evapotranspiration on the } \\
\text { basis of the water and energy balance principle. }\end{array}$ \\
\hline Z & 1990 & Me (1990) & $\begin{array}{l}\text { Assumes that rainfall conforms to Person III distribution, and } \\
\text { through precipitation normalization to determine drought index. }\end{array}$ \\
\hline SPI & 1993 & McKee (1993) & $\begin{array}{l}\text { Reflects the probability of precipitation occurring during a certain } \\
\text { period, which is suitable for monthly or even longer-scale } \\
\text { drought monitoring. }\end{array}$ \\
\hline WDI & 1994 & Moran (1994) & $\begin{array}{l}\text { This index is established by a combination of the differences } \\
\text { between air and land surface temperature and vegetation index, } \\
\text { considering the nearly linear relationship between vegetation } \\
\text { cover and the most theoretical parameter in the crop water stress } \\
\text { index. }\end{array}$ \\
\hline VCI & 1995 & Kogan (1996) & $\begin{array}{l}\text { Overcomes the shortage of anomaly vegetation and normalized } \\
\text { vegetation index, which can effectively monitor the spatiotempo- } \\
\text { ral variation in drought. }\end{array}$ \\
\hline NDWI & 1996 & Gao (1996) & $\begin{array}{l}\text { This index can effectively detect water content in vegetation } \\
\text { canopy and respond promptly when vegetation undergoes water } \\
\text { stress by introducing shortwave infrared bands. }\end{array}$ \\
\hline $\mathrm{CI}$ & 1998 & Zhang (1998) & $\begin{array}{l}\text { Integrates the standardized precipitation index and relative hu- } \\
\text { midity index, which is suitable for near real-time and historical } \\
\text { meteorological drought. }\end{array}$ \\
\hline TVDI & 2002 & Sandholt (2002) & $\begin{array}{l}\text { Characterizes crop water stress through the dry and wet equation } \\
\text { determined by vegetation cover and surface temperature. }\end{array}$ \\
\hline VSWI & 2004 & Haboudane & $\begin{array}{l}\text { This index, combined with the land surface temperature index } \\
\text { and vegetation index, is used for agricultural drought monitoring. }\end{array}$ \\
\hline SC-PDSI & 2004 & Wells (2004) & $\begin{array}{l}\text { This index is self-calibrated PDSI, which can determine model } \\
\text { calibration parameters according to local climate characteristics. }\end{array}$ \\
\hline $\mathrm{K}$ & 2007 & Wang(2007) & $\begin{array}{l}\text { This index, used for meteorological and agricultural droughts, is } \\
\text { defined as the ratio of the relative variability in seasonal rainfall } \\
\text { and relative variability in evaporation. }\end{array}$ \\
\hline VegDRI & 2008 & Brown (2008) & $\begin{array}{l}\text { This is a synthesized drought index that includes information on } \\
\text { vegetation, meteorology, and soil water capacity by using data } \\
\text { mining. }\end{array}$ \\
\hline SPEI & 2010 & $\begin{array}{l}\text { Vicente-Serrano } \\
(2010)\end{array}$ & $\begin{array}{l}\text { This index is a modified SPI, which introduces evapotranspira- } \\
\text { tion data for calculating drought. }\end{array}$ \\
\hline
\end{tabular}

regions. However, PDSI still had limitations because of the fixed time scale. In terms of agricultural drought monitoring, Shafer (1982) and Jackson (1988) proposed the surface water supply index (SWSI) and crop water stress index (CWSI), respectively, after comprehensive consideration of surface water supply and crop water demand, and they both worked well. In 1993, McKee (1993) found that the observed precipitation has a skewed distribution rather than a normal distribution and proposed SPI; SPI has become one of the most popular indices because the calculation is simple and can achieve multi-scale monitoring for different 
types of drought. However, since it only considers precipitation and neglects the influence of evaporation on drought, the method was also incomplete. To integrate the effects of precipitation and evaporation on drought, Vicente-Serrano (2010) established the standardized precipitation and evaporation index (SPEI), which had the multi-scale advantage of SPI and the advantage of considering evaporation of PDSI. SPEI has become one of the ideal drought monitoring tools. Then, Vicente-Serrano (2012) compared the performances of SPI, SPEI, and PDSI with respect to global drought monitoring and found that SPI and SPEI were better than PDSI for hydrological and agricultural drought monitoring and that SPEI was excellent for monitoring summer drought. A recent study established the standardized relative humidity index (SRHI) by applying relative humidity data, and this index can detect the onset start of a drought earlier than SPI and is considered an ideal index for drought warning (Farahmand et al., 2015).

In China, scholars made considerable efforts to build drought monitoring indices continuously and have tried to integrate various meteorological indices to improve monitoring ability. Zhang (1998) proposed the comprehensive index (CI), which made weighted summation of the standardized precipitation index and relative humidity index, and this index is widely used for drought monitoring in meteorological departments of China. Wang (2007) proposed the $\mathrm{K}$ index, which is defined as the ratio of the relative variability in seasonal precipitation and the relative variability in evaporation; it is suitable for monitoring meteorological and agricultural droughts. In summary, the above review indicated that site-based drought monitoring indices have been developed over a long period, and it has become the main method for drought monitoring. In terms of data source, site-based indices mainly rely on the data records of meteorological stations. However, uncertainties still exist with respect to observed datasets, including uneven distribution in space and inconformity in time-series induced by site migration. Although a series of methods have been implemented to enhance observation station network density, such as addition of automatic weather stations, and develop data homogenization methods to correct abnormal sequences caused by non-climatic factors, there are few data records of new time series data and a shortage of stations in key ecological regions, especially in agricultural ecosystems.

\subsubsection{Remote sensing-based drought monitoring}

Since agricultural drought is closely connected to soil moisture and crop water deficit, remote sensing of water inversion in soil and vegetation is an effective way for large-scale agricultural monitoring. Data assimilation methods are generally used to estimate soil moisture (Kumar et al., 2014). Among these methods, thermal inertia models of different soil textures, established by Chen (1999), improved the accuracy of water inversion by introducing parameters of topography and wind field; however, the parameters are difficult to determine in practice. Then, Zhang (2001) integrated the thermal inertia model, heat balance model, and temperature difference model by using temperature differences of the soil and leaves facing the sun and away from the sun, developing a new method of soil moisture inversion on the basis of multi-angled remote sensing data. In addition, by applying the improved IEM model, Rajat Bindlish (2006) obtained an inversion result whose correlation with actual soil moisture was 0.95 . Although microwave remote sensing can work continuously without being influenced by clouds, it is only capable of inverting the soil moisture of the surface $(2-5 \mathrm{~cm})$, while crop roots are usually $10-20 \mathrm{~cm}$ under the surface. Hence, water 
stress in crops cannot be examined accurately, and the result is highly uncertain (Chen et al., 2012). However, accurate estimation of soil moisture at different depths is very important, since it is a key parameter for agricultural drought monitoring. Therefore, despite the limitations of the applying remote sensing method to agricultural monitoring, further studies are still required; the microwave inversion results should be coupled with the terrestrial surface model, and field survey data should be collected to increase inversion accuracy and depth (AghaKouchak et al., 2015).

With respect to crop water deficit, CWSI was developed by analyzing the empirical relationship between air vapor and temperature differences of the canopy and air (Idso et al., 1981). Later, Moran (1994) developed the water deficit index (WDI) on the basis of the two-layer model of the energy balance model, while Gao (1996) proposed the normalized difference of water index (NDWI). To eliminate the influence of both Normalized Difference Vegetation Index (NDVI) spatial variation and other parameters of geography and ecosystem, Kogan (1995) proposed the vegetation condition index (VCI) for drought monitoring, and then Wang (2003) developed the vegetation temperature condition index (VTCI) in 2003. On basis of this, Kogan proposed the vegetation health index (VHI) by linear integration of TCI and VCI (Boken et al., 2004; Kogan et al., 2013), which was proven to be effective in reflecting the drought situation of crops (Mu et al., 2007). In 2004, Haboudane proposed the vegetation supply water index (VSWI), which is a relatively simple synthesis index for vegetation and temperature (Haboudane et al., 2004). Previous studies have shown that VSWI is appropriate for regions with high vegetation coverage, and it is widely applied in practice (Liu et al., 1998). Sandholt (2002) proposed the temperature vegetation drought index (TVDI) to estimate soil moisture on the basis of the relationship between land surface temperature (LST) and vegetation index (VI), which is an important method to reflect agricultural drought conditions through soil moisture monitoring. A hypothesis of TVDI is that NDVI is negatively correlated with LST (Karnieli et al., 2010). However, NDVI is negatively correlated with LST when water is the limitation factor of vegetation growth, whereas NDVI is positively correlated with LST when energy is the limiting factor of vegetation growth. Moreover, TVDI can well explain regions with drought episodes, but failure in performance of agricultural monitoring and earlier warning.

2.2.3 Comprehensive drought monitoring on the basis of both meteorological and remote sensing data

With the introduction of multi-source data, considerable efforts for drought monitoring were made to integrate meteorological and remote sensing data. By a review of recent studies on comprehensive drought monitoring indices, Hao (2015) pointed out that the US drought monitoring (USDM) model is a relatively successful model. However, application of USDM at a regional scale has many uncertainties because of its limited spatial resolution. Based on the classification and regression model, Brown (2008) proposed the vegetation drought response index (VegDRI) by combining meteorological drought indices (SPI and PDSI), the vegetation index, and DEM. The index can provide near real country-scale drought information and has become a model for comprehensive drought monitoring indices. Wu established an integrated drought monitoring model for different growth stage of crops in China (Wu et al., 2013; Wu et al., 2015). Du (2013) developed a synthesis drought index by using TRMM precipitation data, LST data, and VI data in Shandong Province, and it has achieved good 
results. By linear combination, Rhee (2010) proposed a drought monitoring index suitable for arid and humid regions by using a linear combination of LST, NDVI, and TRMM datasets, whereas Zhang (2013) established a meteorological drought index based on satellite-derived precipitation, AMSER-E soil moisture, and NDVI data. In addition, Mu (2013) developed a satellite-based near real drought severity index (DSI) by using land surface evapotranspiration and VI data, which could successfully detect the drought episode in Europe in 2003 and the Amazon drought in 2005 and 2010. Moreover, estimation by DSI is highly correlated with the results of PDSI at a site scale. By comparing different drought indices, Hao and AghaKouchak (2014) proposed the multi-variable drought index (MSDI), which combined precipitation and soil moisture data and is considered a valid drought monitoring index. In addition, AghaKouchak (2015) modified MSDI through introduced ensemble runoff prediction and carried out drought monitoring and early warning in East Africa. Deepthi (2015) proposed the multi-variable drought index (MDI), which comprehensively considers precipitation, runoff, evapotranspiration, and soil moisture and can simultaneously monitor meteorological, agricultural, and hydrological droughts. In addition, scholars recently attempted to assimilate historical data and real-time data to establish a data drive for near real drought monitoring indices (Shah and Mishra, 2015). On the basis of the aforementioned analysis, scholars have made considerable efforts to establish comprehensive drought monitoring indices and obtained valuable results. It should be noted that although several comprehensive drought indices have been proposed, the research is still in the infant stage. Moreover, multi-spatiotemporal scale drought monitoring indices are still required, and comprehensive drought monitoring indices have limitations. For example, although the linear combination method integrated multiple factors, it is difficult to explain the physical implication, whereas the copula function can obtain probability, facilitating risk analysis; however, it only considers the statistical characteristic of data and lacks a description of the physical process.

\subsection{Review of previous studies on agricultural drought monitoring}

To better understand the development stages of studies on agricultural drought monitoring, we searched for papers in the ISI Web of Science by using the terms "agricultural drought" and "drought monitor" on June 26, 2015. Statistics showed that both the number of papers and citations of them increased exponentially (Figure 3), and we also observed an increasing trend when we searched for "agricultural drought" and "drought monitor" in CNKI. The results showed that research on agricultural drought monitoring has become the focus of scholars worldwide, and the trend is significant after 2000.

Since drought is associated with various disciplines, scholars in different areas, such as geography, ecology, meteorology, and disaster have performed systematic studies on drought. To better analyze the studies, we searched the ISI Web of Science with the term "Drought" and obtained a total of 52376 papers (period: 1990-2014, search time: 6/26/2015).Through a literature review, we found large differences in the number of papers of different research orientations. The top three were botany, agronomy, and ecological environment, and they accounted for $25.97 \%, 22.68 \%$, and $20.48 \%$, respectively, of the total number of papers; and water resources and meteorology accounted for $7.98 \%$ and $7.72 \%$, respectively; and geography only accounted for $6.82 \%$. This distribution indicates that vegetation, agriculture, and 
ecological environment are most heavily and directly impacted by drought, and they have attracted worldwide attention (Figure 4).
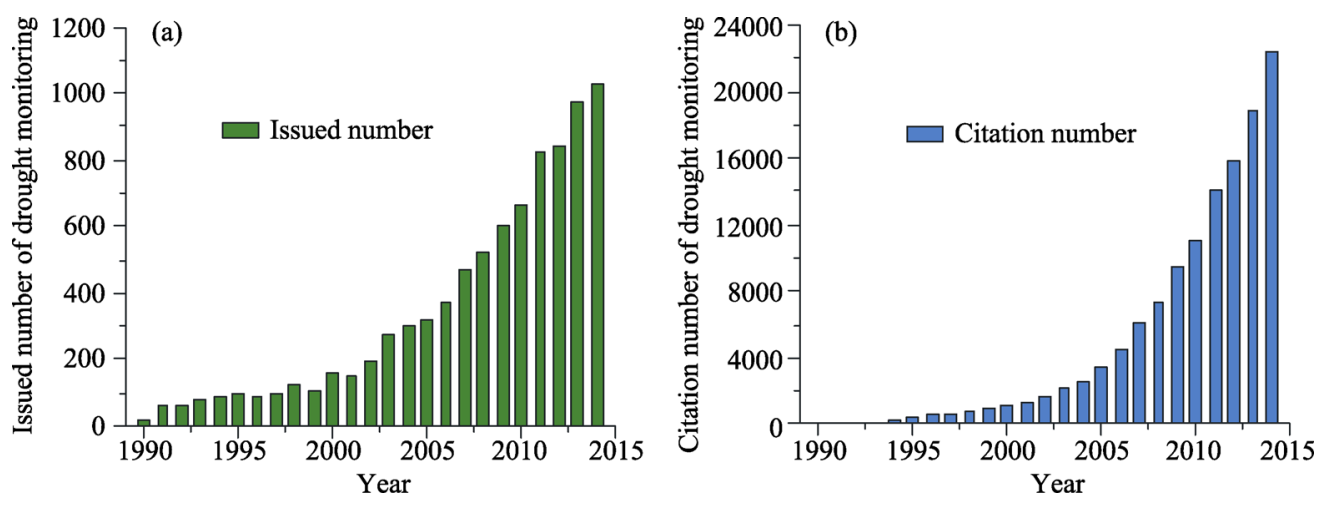

Figure 3 Statistics of issued and citation literatures in agricultural drought monitoring during 1990-2014

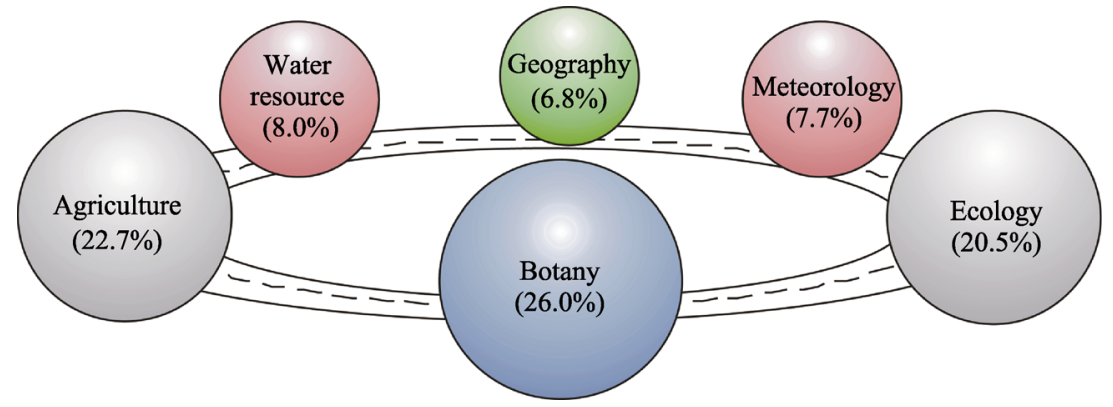

Figure 4 Statistics of issued literature relevant to drought in different subjects

We observed four main characteristics of the studies on agricultural drought monitoring on the basis of the paper review and citation. First, the distribution of research orientation for drought is diverse. Majority of the papers are about the influence of drought on the ecosystem, like on vegetation growth, production, and the fluctuation in carbon storage. In agriculture, previous studies mainly focused on assessing the impact of drought on crop growth and production. The IPCC report pointed out that the production of rice, maize, and wheat in Asia has decreased in the past decades because of increasing drought, mainly reflecting climate warming, frequent ENSO, and an increase in dry days (IPCC, 2007). Geographical and disaster studies focused on the spatial and temporal distribution, mechanism, and reduction of disasters. While papers on disaster spatiotemporal distribution are comparatively abundant and there are also profound studies on the cause of drought with respect to an analysis of the climate, there are few studies on drought monitoring, which is significant for disaster reduction (Du et al., 2013; Mishra and Desai, 2005; Mishra and Singh, 2009; Mishra et al., 2009). Second, the method suggested a transformation of agricultural drought monitoring from traditional single meteorological monitoring indices to meteorology and remote sensing-integrated monitoring indices, and new data mining methods, including classification and regression tree, linear weighting, copula, and Bayes network, were introduced. For example, Brown (2008) integrated VI, meteorological drought index, and auxiliary data to develop the vegetation drought response index, which is widely used in the US for drought 
assessment. Rhee (2010) and Zhang (2013) discussed the performance of drought monitoring from different linear combinations of precipitation, vegetation, and LST in meteorological and agricultural droughts. Anderson (2012) proposed a drought monitoring method by combining multiple soil moisture datasets through the triple collocation analysis method, while Hao (2013) established multi-variable drought monitoring indices by using precipitation and soil moisture data. Third, with respect to the data collection method, traditional ground-based observation cannot reflect spatial characteristics because of its uneven distribution. A combination of gauged data and remote sensing data has become popular in recent studies, especially for remote sensing-based drought monitoring, because of the increase in different types of sensors and enhancement in spatial and temporal resolution. However, relatively short data records have limitations. Thus, we should highlight the construction of long-term surface parameter products by assimilation of multi-source datasets. In addition, development of satellite-based drought monitoring models are needed to enhance our ability to forecast drought, for example, the microwave remote sensed drought model (Kongoli et al., 2012; Rott et al., 2010). Fourth, in terms of drought monitoring products, several global-scale products were widely used, including the PDSI product developed by Dai (2004), SPEI products with a $0.5^{\circ} \times 0.5^{\circ}$ resolution developed by Vicente-Serrano (2010), and remote sensed global terrestrial drought severity index products developed by $\mathrm{Mu}$ (2013). Recently, Hao et al. (2014) released the global integrated drought monitoring and prediction system (GIDMaPS), including the near real-time drought monitoring model and seasonal prediction model, and it can provide global-scale meteorological drought and agricultural drought products. Together, the aforementioned drought products provide data support for global drought monitoring and assessment.

\section{Challenges and prospects of agricultural drought monitoring}

Compared with indices for meteorological drought monitoring, simple indices for agricultural drought monitoring can hardly show the influence of drought on crops and provide a warning in advance by reflecting the drought mechanism. Recently, development of remote sensing has provided opportunities for agricultural drought monitoring. Some studies that tried to monitor drought by means of integrating vegetation index, land surface temperature, precipitation, and other auxiliary data achieved some progress (Du, 2013; Rhee et al., 2010). However, whether the conclusions of these studies on specific regions can be widely applied at different scales still needs to be considered, and we can hardly compare results that ignored the resistance and lag effect of crops to drought; the predicted trend varies with different indices (Christopher, 2012). Considerable bias may exist in the assessment of the results. While previous studies have achieved advance drought warning by using SRHI, results show that this index shows better performance for warning than most current indices (Farahmand et al., 2015). Nevertheless, analysis of this is still limited in qualitative or univariate studies because the extent to which crop production gets impacted and reduced cannot be represented, and research on the agricultural drought mechanism is still a big problem.

Therefore, considering the urgent demand for agricultural drought monitoring in risk management and the developing trend, breakthroughs are needed, both in theory and in practice. Specifically, the following five aspects of agricultural drought monitoring may be 
the main development directions for the future (Figure 5). In theory, we need to further understand the mechanism and process of agricultural drought and identify the influencing factors and feedback mechanism to integrate multiple influencing factors and establish a synthesized drought monitoring model. We also need to build drought monitoring and warning models at multi-spatiotemporal scales, couple the drought monitoring model and crop growth model to bridge the qualitative description to semi-quantitative and even quantitative description for agricultural drought monitoring, and establish a new drought index that can monitor drought as well as predict crop failure. In practice, we need to use multi-source remote sensing data to a greater extent to facilitate agricultural drought monitoring.

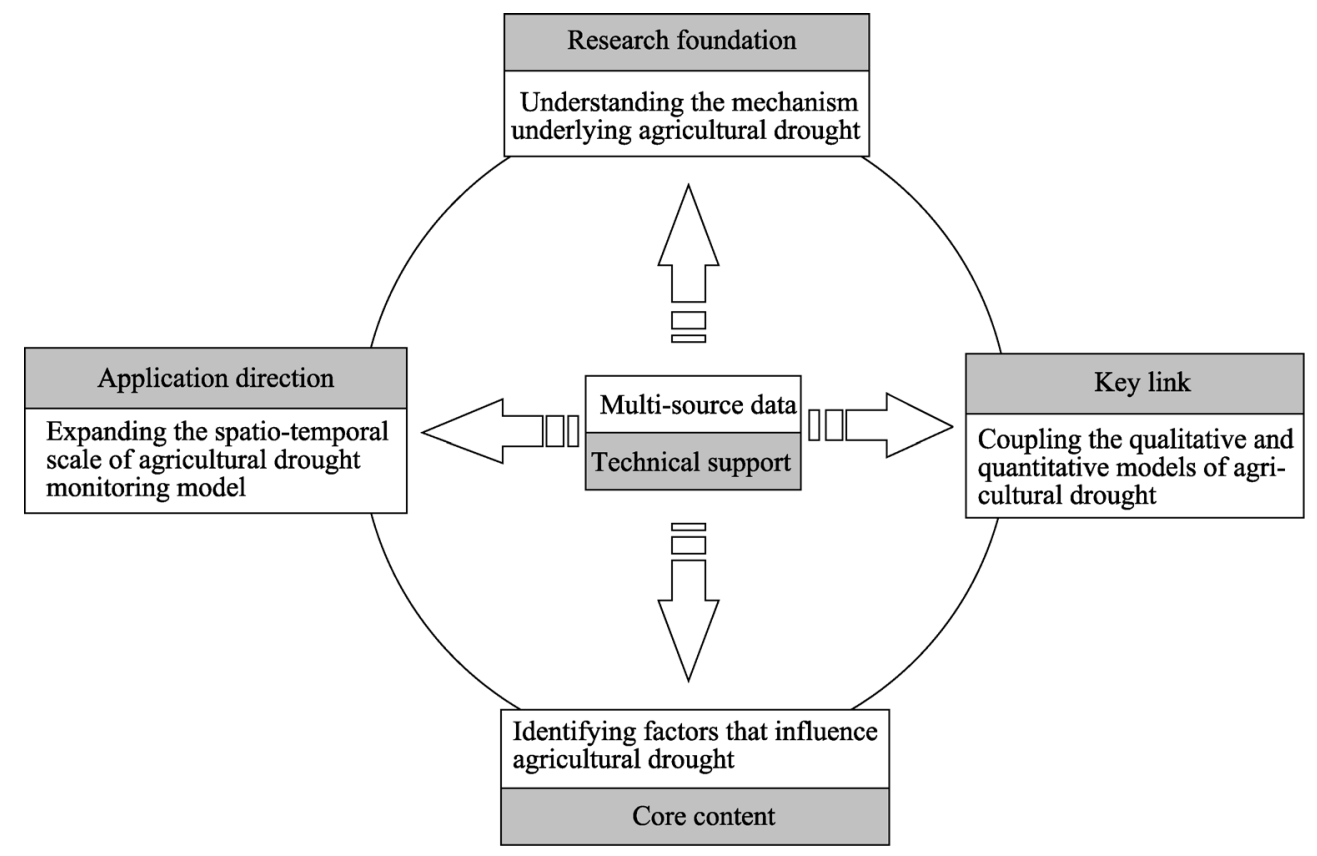

Figure 5 Key research directions of agricultural drought monitoring in the future

\subsection{Understanding the mechanism underlying agricultural drought}

Soil moisture, a key parameter that integrates the responses of climate, soil, and vegetation to water balance and the influence of water balance on vegetation dynamics, plays a very important role in the terrestrial water cycle. Agricultural drought reflects the extent to which soil moisture is lower than crop demand water, resulting in crop wilting and even failure. Since the tolerance to soil water deficit is different among crops and regions, time lags to precipitation shortage and soil moisture deficit also differ, and the difference varies with the growing stage as well. With an increase in water shortage, evaporation decreases and the surface temperature increases, forming a positive feedback process. The precipitation model that neglects the abovementioned process cannot explain agricultural drought monitoring with respect to crop water balance. Currently, the comprehensive response process of crops to precipitation and temperature is still unclear, and we should further understand the crop drought mechanism. We should also make better use of the time lag between water deficiency and crop drought stress for early warning of drought. 
In addition, agronomic parameters are the basic parameters for describing crop growth, and they are, therefore, an important aspect of research on the agricultural drought mechanism. The crop reflectance spectrum is significantly influenced by agronomic parameters, and the red edge, which is closely related to chlorophyll content, is one of the most important parameters. When crops are under water stress, the parameters values will change and further result in the displacement of the red edge. Therefore, analyzing variations in the crop reflectance spectrum by hyperspectral remote sensing provides a new angle for research on the agricultural drought mechanism. Since monitoring models can hardly detect the start and end time of agricultural drought, studies on the mechanism may be a key to solving the problem. Upon understanding the agricultural drought mechanism, we can predict the onset of drought in time and establish an agricultural drought remote sensing model on the basis of crop physiological and ecological characteristics, facilitating prompt measures for reducing drought-related losses and influences.

\subsection{Identify factors that influence agricultural drought}

Agricultural drought is caused by an abnormal decrease in precipitation, and it is influenced comprehensively by land surface temperature, evapotranspiration, soil properties, and physiological or ecological characteristics of the crop. We should pay more attention to factors closely related to agricultural drought in the future, understand the interaction mechanism, screen the key influencing factors to cause variations in drought, and create agricultural drought monitoring models based on multiple geological factors. In practice, since satellite remote sensing can acquire precise spatial and temporal information on the land surface and at a large scale, it is widely used in agricultural drought monitoring. It is considered an ideal data source because it provides not only information on the land surface environment but also information on crop growth, like vegetation index, land surface temperature, and precipitation. By using remote sensing as a data source, we can integrate soil characteristics and topography features and add both environment and crop information in the agricultural monitoring model to achieve the integration of multiple geological factors for drought monitoring.

Currently, some countries have already developed agricultural drought monitoring systems at country or regional scales, and satellite data-driven comprehensive models are being established (Brown et al., 2008). However, integration of remote sensing data with meteorological data obtained by stations has not been achieved. It should be noted that even though remote sensing data can be an effective supplement for meteorological data, because they cover large regions at a high frequency, they cannot fully replace the latter. The reason is that although land surface observation stations are few and unevenly distributed, the data are precise with a long time series and the most important data source for remote sensing data validation. Therefore, it is important to build a bridge between remote sensing monitoring models and meteorological observation models, integrating the advantages of both model types. To achieve this goal, technologies and methods still need improvement. For example, we should build a more complete ground observation network, develop a perfect coupling method, and determine a uniform influencing factor framework.

\subsection{Expansion of the spatiotemporal scale of agricultural drought monitoring models}

The concept of scale, both temporal and spatial scales, is frequently mentioned. For agricul- 
tural drought monitoring, there are intrinsic differences among the results at different spatial and temporal scales. For example, the monitoring result of months may be different from the result of years, and at a different spatial scale, the result may also vary with the input data. Previous studies have tried to create agricultural drought monitoring models at different temporal and spatial scales and achieved some models with good validation results at a regional scale (Du et al., 2013; Rhee et al., 2010). However, most studies were limited to specific regions and time scales, and the scale of the models should be further expanded. Therefore, how to integrate the existing agricultural drought monitoring models and develop new multi-scale agricultural drought monitoring models will be a key question for establishing a drought monitoring platform with multi-spatiotemporal scales in the future.

Agricultural drought monitoring provides information on crop growth and production worldwide, and it facilitates crop production prediction as well. However, since there are differences in the developing stage, technology level, and disaster reduction ability among different countries, the request for agricultural drought monitoring information also varies. Therefore, building an agricultural drought monitoring platform at multi-spatiotemporal scales not only meets the demand of different countries but is also significant for reducing the influence of drought and improving the ability to cope it worldwide. More specifically, (1) at temporal scales, monitoring models should be able to manage early warning at 10 days, a month, a season, a year, and a decade in regular situations, whereas during emergencies, the models should be able to monitor near real-time early warning. (2) At spatial scales, the model should satisfy the needs of the world, different continents, different countries, and different regions. How to achieve a monitoring platform at multi-spatiotemporal scales is a key issue for future research on agricultural drought monitoring.

\subsection{Coupling qualitative and quantitative models for agricultural drought monitoring}

Qualitative description accounts for the most in the results of existing agricultural drought monitoring model, and the lack of quantitative monitoring and warning assessment limits the association between monitoring results and practical loss assessment. Although technological methods for drought monitoring are developing fast, attention to methods for qualitative assessment of the results is still lacking. With the rapid development of numerical simulations and further understanding of the drought mechanism of crops, the crop growth model has made great progress with respect to quantitative assessment of agro-meteorological hazards, and it is considered the core step to push agricultural drought monitoring into the stage for quantitative assessment. The advantage of the crop growth model in agro-meteorological hazard assessment is that the mechanism is clear and it can reflect the active relationship between the growing process; crop production; and temperature, precipitation, and soil moisture at every growth stage. Therefore, we should use functions of the crop growth model when creating agricultural drought monitoring models in the future.

In terms of technology, the spatial crop vulnerable model can be drawn from station-scale vulnerable models through the scale upscaling algorithm, which is a promising method for coupling an agricultural drought monitoring model at a large scale and the crop growth model; it will become the core and critical point of agricultural drought monitoring. On the basis of spatial information, especially the advantage of remote sensing technology, and by improving the integration of indices for crop physiology, morphology, and soil moisture, we 
can achieve the coupling of an agricultural drought monitoring model at a large scale and the crop growth model, and create a remote sensing-based agricultural drought monitoring platform with a clear physical mechanism, multiple factors, and progress and at multiple scales. This is an ideal way for realizing the goal of reducing agricultural hazard loss to the largest extent.

\subsection{Improving the applications of remote sensing data}

Remote sensing is a very important data source for agricultural drought monitoring, and with launching of satellites for different uses, abundant remote sensing data are acquired by scholars to analyze land surface processes. Compared with ground observation data, the biggest challenge for remote sensing data is the short time sequence, which can barely present the variation in drought at a long time scale. The diversified temporal and spatial scales of different data sources also limit the comprehensive use of the data. Although we have developed transforming technology for multi-scale remote sensing data, comprehensive applications have not been completely achieved, especially with respect to applications of microwave remote sensing data for the influence of drought on vegetation (Andela et al., 2013). In future, we should enhance the use of remote sensing in drought monitoring by exploring more land surface parameters and increasing the applications of remote sensing data (Rodell, 2012). Uncertainties of remote sensing data are a key problem with respect to their applications, like the difference in uniformity caused by the change in sensors. Therefore, to develop data assimilation technology, upgrading the comprehensive applications and quantitative estimation of the uncertainties of remote sensing data are important. Finally, successful launches of new types of satellites such as the Soil Moisture Active Passive is offering new opportunities for agricultural drought monitoring, hence increasing the importance of remote sensing data in agricultural drought monitoring (Figure 6).

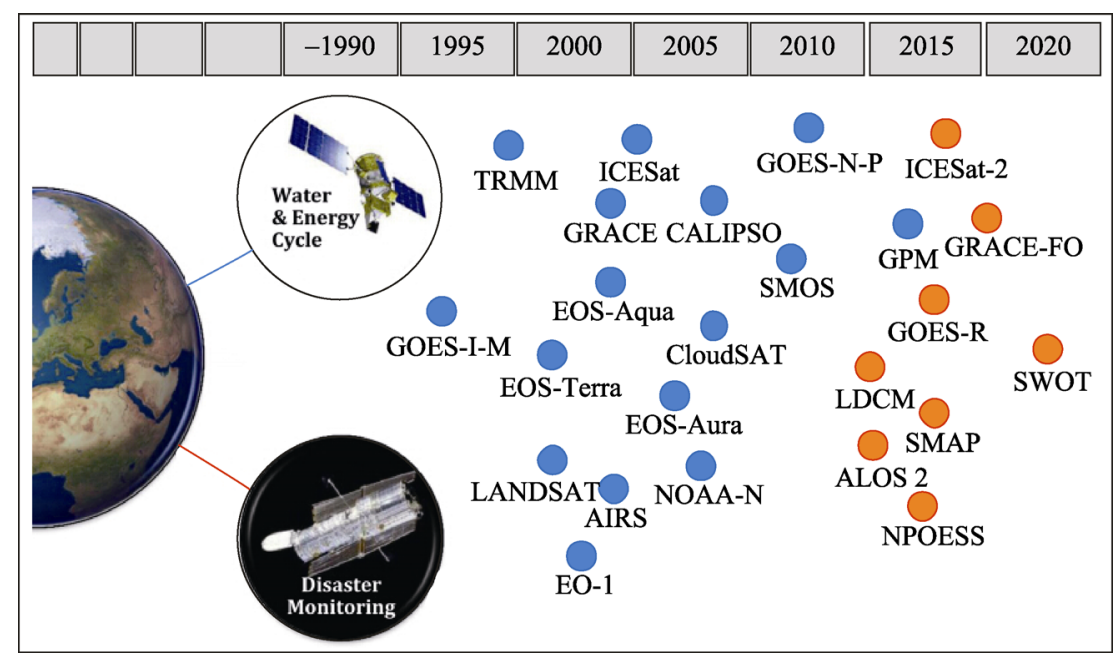

Figure 6 Current and future satellite missions relevant to drought monitoring

\section{References}

AghaKouchak A, 2015a. A multivariate approach for persistence-based drought prediction: Application to the 
2010-2011 East Africa drought. Journal of Hydrology, 526: 127-135.

AghaKouchak A, Farahmand A, Melton F S et al., 2015. Remote sensing of drought: Progress, challenges and opportunities. Reviews of Geophysics, 53: 452-480.

Alley W M, 1984. The Palmer drought severity index: Limitations and assumptions. Journal of climate and applied meteorology, 23(7): 1100-1109.

Andela N, Liu Y Y, van Dijk A et al., 2013. Global changes in dryland vegetation dynamics (1988-2008) assessed by satellite remote sensing: Comparing a new passive microwave vegetation density record with reflective greenness data. Biogeosciences, 10(10): 6657.

Anderson W B, Zaitchik B F, Hain C R et al., 2012. Towards an integrated soil moisture drought monitor for East Africa. Hydrology and Earth System Sciences, 16(8): 2893-2913.

Bindlish R, Jackson T J, Gasiewski A J et al., 2006. Soil moisture mapping and AMSR-E validation using the PSR in SMEX02. Remote Sensing of Environment, 103(2): 127-139.

Boken V K, Hoogenboom G, Kogan F N et al., 2004. Potential of using NOAA-AVHRR data for estimating irrigated area to help solve an inter-state water dispute. International Journal of Remote Sensing, 25(12): $2277-2286$.

Brown J F, Wardlow B D, Tadesse T et al., 2008. The Vegetation Drought Response Index (VegDRI): A new integrated approach for monitoring drought stress in vegetation. GIScience \& Remote Sensing, 45(1): 16-46.

Chen Huailiang, Feng Dingyuan, 1999. Estimate the deep soil moisture methods and models by using remote sensing data. Journal of Applied Meteorology, 10(2): 232-237. (in Chinese)

Chen Huailiang, Zhang Hongwei, Liu Ronghua et al., 2009. Agricultural drought monitoring, forecasting and loss assessment in China. Technology Review, (11): 82-92. (in Chinese)

Chen Shulin, Liu Yuanbo, Wen Zuomin, 2012. Satellite retrieved of soil moisture: An overview. Advances in Earth Science, (11): 1192-1203. (in Chinese)

Dai A, 2011. Drought under global warming: A review. Wiley Interdisciplinary Reviews: Climate Change, 2(1): 45-65.

Dai A, 2012. Increasing drought under global warming in observations and models. Nature Climate Change, 3(1): 52-58.

Dai A, Trenberth K E, Qian T, 2004. A global dataset of Palmer Drought Severity Index for 1870-2002: Relationship with soil moisture and effects of surface warming. Journal of Hydrometeorology, 5(6): 1117-1130.

Du Lingtong, 2013. Drought monitoring model based on multi-source spatial information and its application [D]. Nanjing: Nanjing University. (in Chinese)

Du Lingtong, Tian Qingjiu, Yu Tao et al., 2013. A comprehensive drought monitoring method integrating MODIS and TRMM data. International Journal of Applied Earth Observation and Geoinformation, 23: 245-253.

Fan Jinlong, Zhang Mingwei, Cao Guangzhen et al., 2014. Global drought monitoring initiative with satellite data. Advances in Meteorological Science and Technology, 5: 54-57. (in Chinese)

Farahmand A, AghaKouchak A, Teixeira J, 2015. A vantage from space can detect earlier drought onset: An approach using relative humidity. Scientific Reports, 5: 8553.

Field C B, 2012. Managing the Risks of Extreme Events and Disasters to Advance Climate Change adaptation: Special Report of the Intergovernmental Panel on Climate Change. Cambridge: Cambridge University Press.

Gao B, 1996. NDWI: A normalized difference water index for remote sensing of vegetation liquid water from space. Remote Sensing of Environment, 58(3): 257-266.

Gibbs W J, Maher J V, 1967. Rainfall deciles as drought indicators. Australian: Bureau of Meteorology.

Haboudane D, Miller J R, Pattey E et al., 2004. Hyperspectral vegetation indices and novel algorithms for predicting green LAI of crop canopies: Modeling and validation in the context of precision agriculture. Remote Sensing of Environment, 90(3): 337-352. 
Hao Z, AghaKouchak A, 2013. Multivariate Standardized Drought Index: A parametric multi-index model. Advances in Water Resources, 57: 12-18.

Hao Z, AghaKouchak A, 2014. A Nonparametric Multivariate Multi-Index Drought Monitoring Framework. Journal of Hydrometeorology, 15(1): 89-101.

Hao Z, AghaKouchak A, Nakhjiri N et al., 2014. Global integrated drought monitoring and prediction system. Scientific Data, 1.

Hao Z, Singh V P, 2015. Drought characterization from a multivariate perspective: A review. Journal of Hydrology, 527: 668-678.

Heddinghaus T R, Sabol P, 1991. A review of the Palmer Drought Severity Index and where do we go from here. In: Proceedings of the seventh conference on applied climatology. American Meteorological Society Boston, MA.

Heim R R, 2002. A review of twentieth-century drought indices used in the United States. Bulletin of the American Meteorological Society, 83(8): 1149.

Henry A J, 1906. The Climatology of the United States. Weather Bureau Bulletin Q, Washington D C, 51-58.

Idso S B, Jackson R D, Pinter P J et al., 1981. Normalizing the stress-degree-day parameter for environmental variability. Agricultural Meteorology, 24: 45-55.

IPCC, 2007. Climate Change 2007: The Physical Science Basis: Summary for Policymakers. Intergovernmental Panel on Climate Change Secretariat.

Jackson R D, Kustas W P, Choudhury B J, 1988. A reexamination of the crop water stress index. Irrigation Science, 9(4): 309-317.

Karnieli A, Agam N, Pinker R T et al., 2010. Use of NDVI and land surface temperature for drought assessment: Merits and limitations. Journal of Climate, 23(3): 618-633.

Kincer J B, 1919. The seasonal distribution of precipitation and its frequency and intensity in the United States. Monthly Weather Review, 47(9): 624-631.

Kogan F, Adamenko T, Guo W, 2013. Global and regional drought dynamics in the climate warming era. Remote Sensing Letters, 4(4): 364-372.

Kogan F N, 1995. Droughts of the late 1980s in the United Statesas derived from NOAA polar-orbiting satellite data. Bulletin of the American Meteorological Society, 76(5): 655-668.

Kongoli C, Romanov P, Ferraro P J, 2012. Snow cover monitoring from remote sensing satellites. In: Remote Sensing of Drought: Innovative Monitoring Approaches. CRC Press, 359-386.

Kumar S V, Peters-Lidard C D, Mocko D et al., 2014. Assimilation of remotely sensed soil moisture and snow depth retrievals for drought estimation. Journal of Hydrometeorology, 15(6): 2446-2469.

Li Hailiang, Dai Shengpei, Luo Hongxia, 2012. Status and prospects of agricultural drought monitoring. China Rural Technology, 5: 46-48. (in Chinese)

Liu Li, Zhou Ying, 1998. Drought monitoring based on vegetation supply water index in Guizhou Province. Guizhou Meteorology, 22(6): 17-21. (in Chinese)

Liu Xianfeng, Zhu Xiufang, Pan Yaozhong et al., 2015. Spatiotemporal changes of cold surges in Inner Mongolia between 1960 and 2012. Journal of Geographical Sciences, 25(3): 259-273.

Liu W T, Kogan F N, 1996. Monitoring regional drought using the vegetation condition index. International Journal of Remote Sensing, 17(14): 2761-2782.

Marcovitch S, 1930. The measure of droughtiness. Monthly Weather Review, 58(3): 113-113.

McGuire J K, Palmer W C, 1957. The 1957 drought in the eastern United States. Monthly Weather Review, 85(9): 305-314.

McKee T B, Doesken N J, Kleist J, 1993. The relationship of drought frequency and duration to time scales. In: Proceedings of the 8th Conference on Applied Climatology. American Meteorological Society Boston, MA, $179-183$. 
McQuigg J, 1954. A simple index of drought conditions. Weatherwise, 7(3): 64-67.

Me Zhensheng, Ding Yuguo, 1990. Climate Statistics, 1963. Beijing: Science Press, 1990. (in Chinese)

Mishra A K, Desai V R, 2005. Spatial and temporal drought analysis in the Kansabati river basin, India. International Journal of River Basin Management, 3(1): 31-41.

Mishra A K, Singh V P, 2009. Analysis of drought severity-area-frequency curves using a general circulation model and scenario uncertainty. Journal of Geophysical Research: Atmospheres, 114(D6).

Mishra A K, Singh V P, 2010. A review of drought concepts. Journal of Hydrology, 391(1/2): 202-216.

Mishra A K, Singh V P, Desai V R, 2009. Drought characterization: A probabilistic approach. Stochastic Environmental Research and Risk Assessment, 23(1): 41-55.

Moran M S, Clarke T R, Inoue Y et al., 1994. Estimating crop water deficit using the relation between surface-air temperature and spectral vegetation index. Remote Sensing of Environment, 49(3): 246-263.

$\mathrm{Mu} \mathrm{L}, \mathrm{Wu} \mathrm{B}$, Yan N et al., 2007. Validation of agricultural drought indices and their uncertainty analysis. Bulletin of Soil and Water Conservation, 27(2): 119-122.

$\mathrm{Mu}$ Q, Zhao M, Kimball J S et al., 2013. A remotely sensed global terrestrial drought severity index. Bulletin of the American Meteorological Society, 94(1): 83-98.

Munger T T, 1916. Graphic method of representing and comparing drought INTENSITIES. 1. Monthly Weather Review, 44(11): 642-643.

Palmer W C, 1965. Meteorological drought, 30. US Department of Commerce, Weather Bureau Washington, DC, USA.

Palmer W C, 1968. Keeping track of crop moisture conditions, nationwide: The new crop moisture index. Weatherwise, 21: 156-161.

Rajsekhar D, Singh V P, Mishra A K, 2015. Multivariate drought index: An information theory based approach for integrated drought assessment. Journal of Hydrology, 526: 164-182.

Rhee J, Im J, Carbone G J, 2010. Monitoring agricultural drought for arid and humid regions using multi-sensor remote sensing data. Remote Sensing of Environment, 114(12): 2875-2887.

Rodell M, 2012. Satellite gravimetry applied to drought monitoring. In: Remote Sensing of Drought: Innovative Monitoring Approaches. CRC Press, 261-277.

Rott H, Yueh S H, Cline D W et al., 2010. Cold regions hydrology high-resolution observatory for snow and cold land processes. Proceedings of the IEEE, 98(5): 752-765.

Sandholt I, Rasmussen K, Andersen J, 2002. A simple interpretation of the surface temperature/vegetation index space for assessment of surface moisture status. Remote Sensing of Environment, 79(2): 213-224.

Shafer B A, Dezman L E, 1982. Development of a Surface Water Supply Index (SWSI) to assess the severity of drought conditions in snowpack runoff areas. Proceedings of the Western Snow Conference, 164-175.

Shah R D, Mishra V, 2015. Development of an experimental near-real-time drought monitor for India. Journal of Hydrometeorology, 16(1): 327-345.

Solomon S et al., 2007. The Physical Science Basis. Contribution of Working Group I to the Fourth Assessment Report of the Intergovernmental Panel on Climate Change: 235-337.

Stocker T F et al., 2013. IPCC, 2013: Climate Change 2013: The Physical Science Basis. Contribution of Working Group I to the Fifth Assessment Report of the Intergovernmental Panel on Climate Change.

Van Rooy M P, 1965. A rainfall anomaly index independent of time and space. Notos, 14: 43-48.

Vicente-Serrano S M, Beguería S, Lorenzo-Lacruz J et al., 2012. Performance of drought indices for ecological, agricultural, and hydrological applications. Earth Interactions, 16: 10.

Vicente-Serrano S M, Beguería S, López-Moreno J I, 2010. A multiscalar drought index sensitive to global warming: The standardized precipitation evapotranspiration index. Journal of Climate, 23(7): 1696-1718.

Vicente-Serrano S M, Beguería S, López-Moreno J I et al., 2010. A new global 0.5 gridded dataset (1901-2006) of a multiscalar drought index: comparison with current drought index datasets based on the Palmer Drought 
Severity Index. Journal of Hydrometeorology, 11(4): 1033-1043.

Wang Chunyi, Wang Shili, Huo Zhiguo et al., 2005. Progresses in research of agro-meteorological disasters in China in recent decade. Acta Meteorologica Sinica, (5): 659-671. (in Chinese)

Wang Jinsong, Guo Jiangyong, Qing Jizu, 2007. Application of a kind of K drought index in the spring drought analysis in Northwest China. Journal of Natural Resources, 22(5): 709-717. (in Chinese)

Wang Pengxin, Gong Jianya, Li Xiaowen et al., 2003. Advances in drought monitoring by using remotely sensed normalized difference vegetation index and land surface temperature products. Advance in Earth Sciences, 18(4): 527-533. (in Chinese)

Wells N, Goddard S, Hayes M J, 2004. A self-calibrating Palmer drought severity index. Journal of Climate, 17(12): 2335-2351.

Wu, Jianjun, Zhou Lei, Liu Ming et al., 2013. Establishing and assessing the Integrated Surface Drought Index (ISDI) for agricultural drought monitoring in mid-eastern China. International Journal of Applied Earth Observation and Geoinformation, 23: 397-410.

Wu Jianjun, Zhou Lei, Mo Xinyu et al., 2015. Drought monitoring and analysis in China based on the Integrated Surface Drought Index (ISDI). International Journal of Applied Earth Observation and Geoinformation, 41: 23-33.

Wu Shaohong, Zhao Yan, Tang Qiuhong et al., 2015. Land surface pattern study under the framework of Future Earth. Progress in Geography, 34(1): 10-17. (in Chinese)

Ye Duzheng, 1992. Prediction of Global Change in China. Beijing: China Meteorological Press, 1992. (in Chinese)

Zhang A, Jia G, 2013. Monitoring meteorological drought in semiarid regions using multi-sensor microwave remote sensing data. Remote Sensing of Environment, 134: 12-23.

Zhang Qiang, Han Lanying, Zhang Liyang et al., 2014. Analysis on the character and management strategy of drought disaster and risk under the climatic warming. Advances in Earth Sciences, 1: 80-91. (in Chinese)

Zhang Qiang, Ju Xiaosheng, Li Shuhua, 1998. Comparison of three drought indices to determine and the new index. Meteorological Science and Technology, 2: 49-53.

Zhang Qiang, Zhang Liang, Cui Xiancheng et al., 2011. Progresses and challenges in drought assessment and monitoring. Advances in Earth Sciences, 7: 763-778.

Zhang Renhua, Sun Xiaomin, 2001. Regional differentiation of quantitative estimate crop transpiration and soil water use efficiency by using remote sensing. Science in China: Series D, 31(11): 959-968.

Zhao Junfang, Guo Jianping, Zhang Yanhong et al., 2010. Advances in research of impacts of climate change on agriculture. Chinese Journal of Agrometeorology, 2: 200-205. 